\title{
Two-Tiered Faculty Systems and Organizational Outcomes
}

PamelaS. Tolbert

Many higher education institutions lack systematic organizational procedures for selecting, evaluating, and retaining or releasing non-tenure-track faculty1 (Leslie, Kellams, and Gunne, 1982; Gappa, 1984; Gappa and Leslie, 1993). The organizational consequences are not difficult to foresee. Because few institutions are willing to devote resources to recruitment for non-tenure-track positions, departments are forced to select faculty for such positions from an idiosyncratically generated pool of applicants. Without formal selection criteria, hiring is apt to be strongly influenced by personalistic factors. Furthermore, without regular systems of performance evaluation, decisions about whether to retain faculty or not must be based on restricted information. The limitations of typical personnel arrangements for non-tenure-track faculty, in combination with the very difficult working conditions (for example, last-minute hiring that precludes sufficient course preparation, minimal staff support for organizing course materials, assignment of faculty to overcrowded offices, and so forth), threaten institutions' ability to deliver high-quality education.

An increasing number of books and articles have attempted to spell out "good" organizational practices for employment of part-time and non-tenure-track faculty (Biles and Tuckman, 1986; Berver, Kurtz, and Orton, 1992; Bianco-Mathis and Chalofsky, 1996). However, whether these recommended practices can resolve problems in the employment of such faculty or whether deeper problems are associated with a two-tier employment system for faculty remains an open question.

In this chapter, I present a case study of a department at a large research university in which the use of non tenured faculty increased dramatically over three decades. I begin by examining the historical sources of the expansion. I describe the arrangements that were implemented to resolve these problems. These arrangements exemplify many of the "best management practices" for non-tenure-track faculty mentioned earlier. Based on discussions with non-tenure-track and tenure-track department members and university administrators, I assess the effectiveness of these employment arrangements in resolving problems and the general consequences for the department of having a large contingent of non-tenure-track faculty.

In concluding, I draw general implications from this case for organizational policy and practice involving nontenure-track faculty. I also consider a variety of questions raised for further research on the organizational consequences of the employment of non-tenure-track faculty-questions to which educational and organizational researchers have provided surprisingly few empirical answers.

\section{Non-Tenure-Track Faculty at a Research University: A Case Study}

This case study illustrates organizational responses to a changing mix of faculty.

Department History. Up until a few years ago, teaching modern languages at the university was part of the domain of a single department-the Department of Linguistics and Foreign Languages (LFL). The department was composed of professorial faculty who specialized in linguistics and modern language studies and lecturers who were responsible for teaching introductory and intermediate-level language classes. The use of lecturers to teach modern languages began at the university in the years following World War II; initially, lecturers were responsible for teaching "labs" (small classes that met four days a week and emphasized conversational skills), while professorial faculty organized the labs and delivered weekly lectures to the set of labs that were associated with a course.

Over time, language teaching at the undergraduate level, including the weekly lectures, was increasingly delegated to teaching assistants and lecturers. This delegation was, in large part, a function of a very high demand 
by undergraduates for language courses, created by the foreign language requirement of the college. Because enrollments in language classes were limited for pedagogical reasons, it became necessary to create a large number of classes and sections for courses like elementary Spanish and French. Staffing all these classes with fulltime, tenure-track faculty was not considered economically feasible.

Course offerings of relatively rare languages also proliferated over time, due in part to the establishment of research centers whose funding was contingent on the teaching of particular foreign languages. Limited demand for these courses also made staffing them with full-time faculty problematic. Consequently, instruction in introductory language courses increasingly became the domain of teaching assistants and lecturers.

A number of years ago, the faculty decided that very heavy involvement of graduate students in teaching language classes was not in the best interests of either the undergraduates or the graduate instructors. The result was the further expansion of the number of lecturers employed by the language program. As the number of lecturers grew, so did their acknowledged dissatisfaction with their employment arrangements. Complaints included inadequacies of the procedures used for hiring and making personnel decisions, perceived pay inequities, lack of power in departmental decisions about the curriculum and management of the language, and general relations with the higher-status professorial faculty.

Unlike the latter group of faculty, which had a faculty council to serve as its agent in university decision making and problem solving, there were no official mechanisms or organizations responsible for handling lecturers' grievances. Promotion practices for lecturers became especially conflict-laden as the number of lecturers eligible for promotion in the department rose rapidly over time. Although the department had established promotion paths for lecturers, with specified criteria and procedures for promotion, many lecturers felt that these policies were not consistently applied and that promotion processes were unduly influenced by inappropriately informal criteria. These problems gave rise to increasingly open expression of dissatisfaction with working conditions among many lecturers, along with an exponential increase in the number of complaints filed by lecturers with the administration. The possibility of seeking bargaining status through union certification was discussed.

The administration repeatedly asked LFL to deal with these complaints but the problems were not resolved. A number of factors are likely to have contributed to the lack of effective action by the department. One was the low status traditionally ascribed to the more applied area of language teaching, indicated in part by the comparatively low educational credentials required of language teachers. A substantial number of lecturers had no formal graduate education and some had not received a baccalaureate. Even today, the main criterion for employment is proficiency in a given language, although increasing emphasis is being placed on possession of relevant graduate degrees and demonstrated knowledge of appropriate pedagogy.

Many of the prominent linguists in the department did not view modern language teaching as a substantive academic specialization or as an area to which the department should allocate scarce resources. In addition, although the tenure-track faculty enjoyed the resources that the language courses brought to the department, their distance from this area of teaching provided little motivation to devote time and energy to dealing with difficult governance issues involving lecturers. And finally, norms of academia, which emphasize the autonomy of individual faculty for managing teaching responsibilities, may also have contributed to a general reluctance and lack of preparation among professorial faculty to work collaboratively with lecturers.

Over time, mediating complaints and problems generated by lecturers in modern languages took up an increasing proportion of the associate dean's time, absorbing far more attention than any other unit in the Arts College. The department's inability to resolve the problems finally precipitated the administrative decision to split LFL into two departments-Foreign Language Studies (FLS) and the Department of Linguistics. All of the lecturers were made members of FLS, along with a number of tenured and tenure-track faculty members who responded to the administration's invitation for those interested in language teaching to join the new department. At present, there are approximately sixty-five lecturers in the FLS and fewer than ten tenured or tenure-track faculty. 
Current Organizational Arrangements for Lecturers. The arrangements now in place for the employment of lecturers in the department exemplify many of the standard recommendations for personnel practices involving non-tenure-track faculty. Lecturers are hired on renewable term contracts. They are first hired on a probationary contract, typically for one year, and their performance during the probationary period is assessed by departmental committees. If the assessment is positive, they are usually offered a three-year contract and, finally, a five-year contract. Although the former LFL had instituted promotion policies for lecturers, the lack of specificity and detail in these policies had been one of the key sources of conflict and dissatisfaction among lecturers. The procedures now in place in FLS are much more elaborated and carefully formalized.

The length of the employment contract is linked to faculty rank as either lecturer or senior lecturer. Senior lecturers normally have taught at the college level for at least six years and must be recommended by the department for promotion, based on a peer review not only of their teaching performance but of their service work - contributions as undergraduate advisers, service through committee work, participation in developing the curriculum, and so forth. University policies now prescribe that lecturers who have been appointed for at least three years be given one-year advance notice of termination. A few faculty are still hired as teaching associates or visiting lecturers (explicitly temporary positions), but fewer hold such positions than in the old LFL. Most lecturers are hired on a full-time basis; if that is not possible, the department tries to hire people for at least 50 percent time so they are eligible to receive benefits. The teaching load for full-time lecturers is three courses per semester. To qualify for full-time status, lecturers must sometimes teach multiple languages (for example, several sections of Spanish, along with a section of Tagalog). Professorial faculty normally teach two courses each semester but also have responsibility for research.

Lecturers receive many of the same benefits as regular faculty. Compensation policies are based on equity considerations, and many senior lecturers receive relatively generous salaries (comparable to those of many assistant and associate professors in the university). On average, however, lecturers' salaries are noticeably lower than those of tenure-track faculty, and the benefits they receive that are tied to salary levels (for example, retirement and life insurance) are also generally lower. Some research support (for example, funding for attending professional meetings) is available for senior lecturers, according to university policy, although at a lower level than professorial faculty receive. FLS has established a departmental fund to provide similar levels of support for lecturers as well. Recently, a university-level committee recommended provision of funded leaves to nonprofessorial faculty for professional development, but this policy has not yet been implemented.

Last year, the department responded to pressures from the administration by elaborating formal review standards and procedures for senior lecturers. These provide the basis for discipline and dismissal, as well as for merit awards. The administration originally asked to have such reviews done annually, but when faced with strenuously made arguments about the amount of administrative work required, they finally settled on ten-year reviews. In effect, most senior lecturers will thus be subject to review two or three times in the course of their employment. Many senior lecturers in the department were concerned about these reviews (in much the same way that tenured faculty are often concerned about post-tenure reviews). Implementation of the procedures and reviews have resulted in some dissatisfaction among senior lecturers who received unsatisfactory evaluations, but in the main, most view the current system as more equitable and less subject to idiosyncratic influences than the arrangements under LFL.

Organizational Outcomes. Although significant efforts have been made to include lecturers as full-fledged members of the department, and the formalization and clarification of hiring and review procedures is seen as a major improvement over past practices, there is still ongoing tension between lecturers and professorial faculty. In part, this tension is probably a residual effect of earlier relations between professorial staff and lecturers in LFL and may simply take time to dissipate. Unfortunately, some of the old tensions were refueled soon after FLS was created because economic pressures at the university led to a reduction in the number of lecturers and, concomitantly, to increases in class sizes. Originally, it was proposed that classes be expanded from twelve to twenty; after some negotiation, course enrollment was capped at fifteen. As a result of this, most probationary and short-term lecturers were not rehired. Although none of the positions of longer-term lecturers were 
eliminated, concerns about job security continue to be very salient to many lecturers, and this contributes to perceptions of a we-them division between those who are eligible for tenure and those who are not.

An additional complication to the establishment of smooth faculty relations arose at about the same time the LFL was split into two departments. The faculty council of the university, concerned about potential exploitation of lecturers on campus, passed a resolution making lecturers a part of the faculty, and giving them voting rights in departmental issues "directly related to their roles within the college or school and within the department." The legislation did not, however, offer specific guidelines for determining how to define such issues. In consequence, the legislation has not resolved disputes between tenure-track faculty and lecturers over decision-making rights and responsibilities and may have actually fueled new ones.

Nevertheless, both faculty groups feel that there are a number of substantial advantages to the university's arrangements for teaching modern languages over assignment of such courses to teaching assistants. Lecturers are often more motivated to perform well as teachers because of their long-term investment in the role; teaching assistants are more apt to treat such work as a short-term "dues-paying" part of their graduate education.

Moreover, because of their ongoing involvement in language instruction, lecturers are both more willing and able to contribute to course planning. The decreased reliance by FLS on visiting lecturers and teaching associates is also viewed as having had a positive impact on the quality of teaching because, in the past, many instructors were hired at the last minute with little provision for class preparation or general orientation to the department and to teaching.

Although there is still friction between professorial and lecturer faculty members, changes in policies have helped to reduce lecturers' general dissatisfaction with their relationships with professorial colleagues. Also, most recognize the comparatively advantaged employment position of lecturers in the university relative to those in other institutions.

The large number of lecturers in the department has also had an impact on FLS's hiring of tenure-track faculty. Because professorial faculty are responsible for working closely with lecturers in a given language area and helping to manage the organization of the language classes, evidence of a real concern with the practical issues of providing language instruction and the ability to handle interpersonal and administrative issues in program provision have become important criteria in professorial-level hiring and promotion processes.

Because program administration takes up a substantial portion of professorial faculty's time, it is not clear that they have enough time for research. Nonetheless, promotion to tenure is still based on traditional academic criteria that give heavy weight to research performance: publications, grants, and peer evaluations. The two untenured professors in the department who were recently hired had each developed reasonably strong track records of research; thus, their ability to meet tenure criteria seemed likely at the time of their hiring. Whether brand new Ph.D.'s normally could manage starting a research program while also administering the language programs is unclear.

\section{Organizational Implications}

Although the empirical generalizability of any case study is subject to question, the initial reluctance of LFL to institute employment arrangements that were accepted by lecturers as equitable and consistent certainly parallels the observed failure of many institutions to implement such systems for non-tenure- track faculty. Hence, this case may offer some useful insights into the reasons for general organizational resistance to rationalizing and formalizing employment arrangements for this set of faculty, as well as the consequences of such resistance. Although the fact that the department was part of a large research university might suggest that any conclusions should be limited to other research universities, there is little reason to suspect that the tensions that affect the relationship between tenure-track and non-tenure-track faculty in this context are any less likely to arise in other institutions. 
What conclusions can be drawn for other institutions? First, implementing systematic procedures for making decisions regarding the hiring and continued employment of non-tenure-track faculty is critical to maintaining good relations among tenure-track and non-tenure-track faculty in a department-relations that can affect a department's ability to provide high-quality education. Employing faculty on a casual basis without minimal levels of instructional support severely limits the ability of even the most talented and motivated individuals to present subject matter in an organized and intellectually engaging manner (Gappa, 1984; Gemmill, 1984; Pratt, 1997).

What is not usually acknowledged is that non-tenure-track faculty are often inclined to attribute negative experiences of their employment situation to the tenure-track faculty and to view them, at best, as self-absorbed and insensitive and, at worst, as intentionally exploitative. This, in turn, is likely to have an impact on the overall quality of teaching in a department because divisions within the faculty can impede the sharing of experiences and knowledge that enhance individuals' teaching performance and limit flows of information that are needed to improve or develop the curriculum. In addition, unpleasant and contentious collegial relations can impede teaching performance by affecting faculty morale and motivation. Thus, more elaborated and formalized procedures and criteria for hiring and evaluating the performance of non-tenure- track faculty can reduce general dissatisfaction with the employment situation and contribute to the effective accomplishment of a department's educational function.

Second, professorial faculty are unlikely to initiate organizational procedures for hiring, evaluating, and making decisions about continuing employment of non-tenure- track faculty. There are entirely rational reasons for this lack of initiative. First, as long as positions are subject to elimination by administrative fiat, efforts to create and implement careful selection and evaluation procedures may turn into wasted expenditures of time and energy. Moreover, there is a strong disincentive to develop systematic personnel procedures for non-tenure-track faculty, because the development of such procedures can make the practice of using non-tenure-track faculty increasingly credible and justifiable, thus weakening faculty's claims for additional tenure-track positions.

Third, the establishment of systematic employment procedures for non-tenure track faculty is likely to require active administrative sponsorship. Although faculty may be reluctant to devote time to creating and implementing formal employment criteria, they are clearly in a better position to determine the criteria for selection of fellow faculty in a given field and to evaluate teaching performance. Therefore, the administration should be prepared to offer incentives to faculty to undertake such activity. Positive incentives (in the form of additional compensation or release time from other activities for such administrative work) are more likely to produce better outcomes than empty appeals or threats. In addition, because faculty are sensitive to the potential costs of validating the use of non-tenure-track positions by rationalizing employment arrangements, the administration should work with faculty to develop policy concerning the absolute number of non-tenure-track positions for a department, or even better, the ratio of tenure-track to non-tenure-track positions in a department and in the institution as a whole.

Fourth, waiting until there is a critical mass of non-tenure-track faculty before trying to formalize and implement organizational procedures involving such faculty is a strategic administrative error. Consistent with some of the more general research on organizational demography (for example, South, Bonjean, Markham, and Corder, 1982; Tolbert, Simons, and Andrews, 1995), the case suggests that the presence of a large number of nontenure-track faculty in a department contributes to the development and entrenchment of a strong sense of wethem division. The substantial increase in the proportion of lecturers in the department was the result of policies adopted both by the university and the original LFL without careful consideration of the staffing arrangements that would be necessitated or the degree to which these arrangements would be very counterproductive to collaborative relations. Because the increased use of non-tenure-track faculty in many institutions is likely to be less a result of fully analyzed, strategic decisions than of efforts to adapt to immediate exigencies, administrators or faculty are unlikely to anticipate the potential divisions between tenure-track and non-tenure-track faculty.

However, once generated, such divisions take their toll on departmental relations, even after the material conditions that may have been associated with such divisions are changed. Recognition of the general effects of departmental composition on group relations led some members interviewed for the case study (including some lecturers) to argue strongly for policies that set close limits on the relative proportion of lecturers in a department. 
But it is not clear that policies alone can completely forestall such divisions. The proportionate make-up of different groups of faculty may well have an independent effect on the ability of the department to come to consensus.

\section{Long-Term Implications}

Although the pros and cons of the use of non-tenure-track faculty have long been the subject of heated debate (see, for example, O'Toole, Van Alstyne, and Chait, 1979), empirical evidence on the long-term organizational consequences of such use is surprisingly sparse. We know very little about what effect the increasing use of nontenure-track faculty might have in the short- or long-term on the stability of revenue-expenditure balances, revenues from grants and contracts, changes in tuition rates, institutional prestige and reputation, and other organizational outcomes. Although logical arguments support claims that tenure systems are both economically efficient (McPherson and Winston, 1988; Carmichael, 1988; Ehrenberg, Pieper, and Willis, 1995), and inefficient (Chait and Ford, 1982), empirical data have not been used to test and verify these claims. Hence, there is clearly an important need for more systematic research on the actual outcomes for higher education institutions of relying more or less on heavily on non-tenure-track faculty.

Perhaps more troublesome potential outcomes involve the occupational effects of growth in the number of non-tenure-track faculty. One potential outcome, which has often been alluded to in studies of non-tenure-track faculty (see American Association of University Professors, 1992; Rhoades, 1996; Tolbert, 1997), is the deinstitutionalization of tenure as an employment system. To argue that academic freedom must be protected for those involved in the generation of new knowledge, but not for those who are involved exclusively or largely in the transmission of knowledge, does not seem defensible. Thus on logical grounds (versus purely economic grounds), unless tenure is provided for all long-term faculty members, its necessity and legitimacy is problematic. But the empirical support for such logical arguments is lacking. One possible approach to exploring whether the use of non-tenure-track faculty is indeed likely to lead to the de-legitimation of tenure is to examine whether the proportion of non-tenure-track faculty in institutions at one point in time affects changes in the proportion at later time points. A significant positive effect, net of other influences, could be taken as an indicator of the deinstitutionalization of the tenure system.

A common concern expressed by proponents of tenure is that without such an employment arrangement, the ability of the academic profession in the United States to attract men and women of sufficient caliber to maintain the current national preeminence among higher education systems would decline sharply. Although changes in labor professional markets occur very slowly (Freidson, 1994), the impact of the elimination of tenuretrack positions on entry into the profession might be gauged by systematic comparison of the rates of application and the quality of graduate applicants in fields where there has been a trend to a high ratio of non-tenure-track positions with those in fields where non-tenure-track positions have been less common.

In sum, the short-term negative organizational outcomes that can accompany the employment of faculty in non-tenure-track positions can probably be minimized by implementing preventive personnel policies before conflicts arise. However, the actual economic and reputational outcomes to an institution that arise over the long run from the employment of non-tenure-track faculty are more difficult to assess in the absence of systematic research. In the longer term, the implications for higher education of the decline of tenure, which are foreshadowed by the increasing use of non-tenure-track faculty, are both elusive and problematic. Such long-term issues merit much more extensive research as a basis for informed and effective policy.

\section{Note}

1. I prefer the term non-tenure-track to part-time faculty because it defines more precisely the group that is of concern to most analysts. I also use the term professorial faculty to designate tenure-track faculty, based on conventional ranks for such faculty (assistant professor, associate professor, and so forth). 


\section{References}

American Association of University Professors, Committee G. "Report on the Status of Non-Tenure- Track Faculty. Academe, 1992, Nov./Dec., 39-48.

Berver, K., Kurtz, D., and Orton, E. “Off the Track, but in the Fold. Academe, Nov./Dec. 1992, $27-29$.

Bianco-Mathis, V., and Chalofsky, N. The Adjunct Faculty Handbook. Thousand Oaks, Calif.: Sage, 1996.

Biles, G., and Tuckman, H. Part-time Faculty: Personnel Management. New York: Macmillan, 1986.

Carmichael, L. "Incentives in Academics: Why is there Tenure? Journal of Political Economy, 1988, 96 (4), 453-472.

Chait, R., and Ford A. Beyond Traditional Tenure. San Francisco: Jossey-Bass, 1982.

Ehrenberg, R., Pieper P., and Willis, R. "Would Reducing Tenure Probabilities Increase Faculty Salaries? NBER Working Paper Series, no. 5150. Cambridge, Mass.: National Bureau of Economic Research, 1995.

Freidson, E. Professionalism Reborn: Theory, Prophecy and Policy. Chicago: University of Chicago Press, 1994.

Gappa, J. Part-time Faculty: Higher Education at a Crossroads. ASHE-ERIC Higher Education Research Report no. 3. Washington, D.C.: Association for the Study of Higher Education, 1984.

Gappa, J., and Leslie, D. The Invisible Faculty. San Francisco: Jossey-Bass, 1993.

Gemmill, J. “Course by Course, Year by Year. In M. E. Wallace (ed.), Part-time Academic Employment. New York: Modern Language Association, 1984.

Leslie, D., Kellams, S., and Gunne, G. M. Part-time Faculty in American Higher Education. New York: Praeger, 1982.

McPherson, M., and Winston, G. "The Economics of Academic Tenure: A Relational Perspective. In D. Breneman and T. Youn (eds.), Academic Labor Markets and Careers. New York: Falmer Press, 1988.

Pratt, L. “Disposable Faculty: Part-Time Exploitation as Management Strategy. In C. Nelson (ed.), Will Teach for Food. Minneapolis: University of Minnesota Press, 1997.

O'Toole, J., Van Alstyne, W., and Chait, R. Tenure: Three Views. New York: Change Magazine Press, 1979.

Rhoades, G. "Reorganizing the Faculty Workforce for Flexibility." Journal of Higher Education, 1996, 67 (6), 626659.

South, S., Bonjean, C., Markham, W. T., and Corder, J. "Social Structure and Intergroup Interaction: Men and Women of the Federal Bureaucracy." American Sociological Review, 1982, 47 (3), 587-599.

Tolbert, P., Simons, T., and Andrews, A. "The Effects of Gender Composition in Academic Departments on Faculty Turnover." Industrial and Labor Relations Review, 1995, 48 (2), 562-579.

Tolbert, P. "Changing Employment Structures: The Case of Academia." Working paper, Department of Organizational Behavior, School of Industrial and Labor Relations, Cornell University, 1997. 